\title{
REVIEW
}

Open Access

\section{Safety and efficacy of elagolix (with and without add-back therapy) for the treatment of heavy menstrual bleeding associated with uterine leiomyomas: a systematic review and meta-analysis}

\author{
Mustafa Ali ${ }^{1}$, Aruna Kumari Hira², Haris Jawaid ${ }^{1 *}$, Faiza Zakaria ${ }^{1}$ and Zehra Somjee ${ }^{1}$
}

\begin{abstract}
Background: Heavy menstrual bleeding (HMB) is a common clinical finding in patients with uterine leiomyomas that can negatively impact their quality of life. Recently, a novel oral $\mathrm{GnRH}$-antagonist (elagolix) has emerged as a possible therapeutic agent for this ailment. Herein data was pooled from clinical trials assessing the safety and efficacy of elagolix with and without add-back therapy.

Main text: PubMed and Cochrane library were systematically searched for RCTs that measured the efficacy and safety of elagolix for the treatment of uterine fibroid-associated HMB. All safety and efficacy endpoints were compared between elagolix-alone, elagolix w/add-back therapy, and placebo. The primary efficacy endpoint was defined as the number of women who achieved menstrual blood loss (MBL) $<80 \mathrm{ml}$ and a reduction in MBL from baseline of $>50 \%$ at the end of treatment. Secondary outcomes assessed included change in hemoglobin levels, incidence suppression of bleeding and amenorrhea, and the incidence of adverse events. The random effects model was used to pool data, and heterogeneity was assessed using $\mathrm{l}^{2}$.

Our search identified 4 clinical trials meeting our PICO criteria, with a total of 916 patients. Analysis of the primary outcome revealed that elagolix-alone was the most effective treatment compared to both placebo $(\mathrm{LOR}=3.47, \mathrm{Cl}$ $\left.=3.03-3.91, p=0.000, I^{2}=0.0 \%\right)$ and add-back therapy $\left(\mathrm{LOR}=0.64, \mathrm{Cl}=0.12-1.16, \mathrm{p}=0.016, \mathrm{I}^{2}=43.1 \%\right)$. Furthermore, both elagolix groups (irrespective of add-back therapy) observed a significant improvement in posttreatment hemoglobin levels as compared to the placebo group (elagolix-alone vs PBO: $\mathrm{LOR}=1.44, \mathrm{Cl}=0.66-2.22$, $I^{2}=66.0 \%, p=0.000$; elagolix-w/add-back therapy vs PBO: $L O R=1.22, C l=0.78-1.66, I^{2}=0.0 \%, p=0.000$ ). Concerning safety, while elagolix without add-back therapy had the highest overall incidence of adverse effects (elagolix-alone vs placebo $L O R=0.84, C l=0.48-1.20, I^{2}=7.8 \%, p=0.000$; elagolix-alone vs elagolix-w/add-back $L O R=0.68, C l=0.09-1.26, p=0.024, I^{2}=64.6 \%$ ), the incidence of serious (life threatening) adverse events between all 3 treatment groups was not statistically different. The inclusion of add-back therapy with elagolix made the treatment noticeably safer (elagolix-w/add-back vs placebo: $L O R=0.19, \mathrm{Cl}=-0.10$ to $0.48, \mathrm{I}^{2}=0.0 \%, \mathrm{p}=0.194$ ) without seriously compromising its efficacy.
\end{abstract}

\footnotetext{
* Correspondence: haris.jawaid1999@gmail.com

'Dow Medical College, Dow University of Health Sciences, Karachi, Pakistan

Full list of author information is available at the end of the article
}

() The Author(s). 2021 Open Access This article is licensed under a Creative Commons Attribution 4.0 International License, which permits use, sharing, adaptation, distribution and reproduction in any medium or format, as long as you give appropriate credit to the original author(s) and the source, provide a link to the Creative Commons licence, and indicate if changes were made. The images or other third party material in this article are included in the article's Creative Commons licence, unless indicated otherwise in a credit line to the material. If material is not included in the article's Creative Commons licence and your intended use is not permitted by statutory regulation or exceeds the permitted use, you will need to obtain permission directly from the copyright holder. To view a copy of this licence, visit http://creativecommons.org/licenses/by/4.0/. 
Conclusion: High-quality evidence from 4 trials suggests that elagolix is an effective treatment for leiomyomaassociated HMB, with a marked improvement in all efficacy endpoints. Furthermore, the inclusion of add-back therapy in the treatment regimen should be considered as it mitigates the hypoestrogenic effects of elagolix.

Keywords: Elagolix, Uterine leiomyoma, Heavy menstrual bleeding, Meta-analysis, Add-back therapy

\section{Background}

Uterine fibroids (leiomyomas) are benign myometrial monoclonal tumors that have been classified as the most common gynecological disorder occurring in women worldwide [1] . By estimation, $70 \%$ of women by the age of 50 will show the presence of uterine fibroids, out of which $30 \%$ will be symptomatic. Patients with uterine fibroids may also experience a plethora of symptoms such as abnormal uterine bleeding, pelvic pain, dyspareunia, obstructive effects on bladder or rectum, and infertility, among others [2]. According to a global survey, 59.8\% of women with the diagnosis of uterine fibroids self-reported heavy and prolonged vaginal bleeding compared to those without fibroids (37.4\%) [3].

Treatment and management of this disease varies based on the clinical presentation. Asymptomatic patients and those with no intention of conceiving require no special treatment and are managed conservatively with periodic monitoring [4]. In contrast, symptomatic patients may pursue both surgical and pharmacological avenues. While surgical hysterectomy remains the only true curative solution, its invasive and highly intensive nature bars it from being the first approach. The preferred approach usually involves either pharmacological therapy such as gonadotropin-releasing hormone agonists and antagonists, or selective progesterone receptor modulators (SPRMs), or surgical options such myomectomy and laparoscopic techniques (such as minilaparotomy-assisted vaginal surgery) $[5,6]$.

While numerous different pharmacological approaches to treating uterine fibroids are available, the current fore-runners with the strongest evidence-base include GnRH agonists and SPRMs [6]. Moreover, it is not uncommon in such cases to include add-back therapy of some sort (estrogen, progesterone, or a combination of both) in the therapeutic regimen so as to offset the hypoestrogenic effects of these drugs [7].

Recently, a novel GnRH antagonist (elagolix) has garnered attention with its potential role as an oral treatment option for HMB associated with uterine fibroids having become an area of interest. The role of elagolix for the treatment of endometriosis-related pain has been unequivocally proven and cemented by previous studies $[8,9]$, notably Ezzati et al. [8]. However, major clinical trials evaluating its efficacy and safety for management of heavy menstrual bleeding in leiomyoma patients have only concluded relatively recently, with a few that are still underway (NCT03886220, NCT03271489) [10, 11].

Recently, the results from two phase 3 trials have been published, shedding new light on elagolix as a potential treatment for uterine fibroid-associated menorrhagia, and necessitating an evaluation of both its efficacy and safety in this context. The primary focus of this study would be to undertake a careful analysis of all evidence available, both new and old, in order to reach a consensus as to the role of elagolix with and without add-back therapy in reducing heavy menstrual bleeding in patients as the primary endpoint. Other safety and efficacy outcomes including its impact on the menstrual cycle (amenorrhea or suppression of bleeding), effect on hemoglobin levels, and any adverse effects during the course of treatment will also be evaluated as secondary endpoints.

According to a study, $24 \%$ of women considered the debilitating effects of uterine fibroids a major factor behind failed career ambition [12]. Specifically, HMB in women was revealed to profoundly impact their daily quality of life, preventing them from fully engaging in family, professional, and social activities [13]. In addition to lower productivity, and affecting their school and work, it may also lead to long-term health consequences such as anemia due to iron deficiency [14]. It is evident that uterine fibroids contribute to a massive economic burden for women as well as healthcare systems. Results of this meta-analysis may assist healthcare professionals reach another safe and cost-effective option with the potential to be at the forefront of medical management for this disease, thereby earning the affected women a welldeserved respite.

\section{Main text}

\section{Methodology}

Randomized clinical trials were selected for this review and meta-analysis, based on the PICO criteria described as follows. The population of the study included nonpregnant, premenopausal adult females diagnosed with uterine leiomyoma complaining of heavy menstrual bleeding (menstrual blood loss $>80 \mathrm{ml}$ during at least 2 consecutive menstrual cycles). Patients in the intervention group received elagolix with or without add-back therapy, while the control group was only given placebo. The primary outcome assessed was the number of women without heavy menstrual bleeding at the end of 
treatment. Additionally, multiple secondary endpoints including suppression of bleeding (spotting allowed), amenorrhea (no spotting allowed), changes in hemoglobin levels, and serious and total adverse events were also assessed.

A comprehensive literature search of PubMed, PMC central, Cochrane Library, and Google Scholar was conducted by 2 independent reviewers using a search string composed of the following key-terms: "Elagolix," "orilissa," "menstrual bleeding," "menorrhagia," "fibroids," and "leiomyoma." All studies published from January, 2000, to 1 January, 2021 (date of last search), with full texts available in English were considered for analysis. Reviewers screened studies by title and abstract, and the full-text article was referred to where more information was needed. In the event of any disagreements, a third reviewer was consulted. Relevant data was extracted from the selected studies using piloted forms by 2 independent reviewers and was stored electronically in a spreadsheet. This extracted information included year of study, lead author/trial name, design, inclusion/exclusion criteria, population demographics and baseline clinical characteristics, details of interventions and controls including dosages, duration of treatment, the outcomes of interest described above including their respective follow-up periods, and any funding sources. Studies were included in the systematic review and meta-analysis if they were RCTs and met the PICO criteria described above. In case of multi-armed trials with different dosages of elagolix, only those arms with $600 \mathrm{mg} /$ day were included in the analysis as they were consistently reported by all included studies. Similarly concerning addback therapy, only regiments including $1.0 \mathrm{mg}$ estradiol were included to allow for a fair pooling of results. A PRISMA flow diagram was used to illustrate the search strategy results [15].

Risk of bias in individual studies was assessed using the Cochrane Risk of Bias Tool for parallel, independent randomized clinical trials (CRoB Tool) [16].

Direct pairwise meta-analysis was used to pool data from these studies using the Mantel-Haenszel random effects model. Log-odds ratio (LOR) with 95\% confidence intervals was the chosen effect estimate, and heterogeneity was reported as $\mathrm{I}^{2}$. Forest plots were constructed to visualize the differences in outcomes between the 2 interventions and placebo. Funnel plots were constructed and Harbord's test was performed to statistically assess any publication bias. Leave one out sensitivity analysis was also conducted to ensure that a single study was not driving the results.

\section{Results}

Our search strategy identified 3 publications [17-19], reporting results from 4 multi-armed randomized controlled trials that met our criteria for inclusion in the review (Fig. 1). Data from a total of five arms (from the 4RCTs) which met the previously described PICO criteria were included in the meta-analysis.

The basic study characteristics and the outcomes assessed by the included trials are shown in Tables 1 and 2 respectively. Table 3 shows the basic demographics and baseline clinical characteristics of study participants. It is evident that while there is no notable variation in the participant ages between the trials, the BMI of patients in Elaris UF-1 and UF-2 is higher compared to the other studies. Both of these patient characteristics, however, are similar between treatment groups in all trials. Additionally, patient hemoglobin levels, and baseline menstrual blood loss, are observed to be similar between all treatment groups and studies. While the same is generally true for uterine volume, there is a notable exception (Carr 300). Uterine volumes in this case are generally higher than in other trials, and significant within-group variation can also be appreciated.

Results of quality assessment of individual studies conducted using the CRoB tool are shown in Table 4. Both phase 3 trials and the phase $2 \mathrm{~b}$ study were evaluated to have an overall low risk of bias. There were some concerns regarding the phase $2 \mathrm{a}$ trial as there was insufficient information to make an assessment regarding randomization, blinding, and allocation concealment.

With respect to the primary outcome (number of women with menstrual blood loss $<80 \mathrm{ml}$ and a reduction of $>50 \%$ from baseline), the pooled analysis revealed that elagolix without add-back was significantly more effective as compared to both placebo (LOR = 3.47, $\left.\mathrm{CI}=3.03-3.91, \mathrm{p}=0.000, \mathrm{I}^{2}=0.0 \%\right)$ and add-back $\left(\mathrm{LOR}=0.64, \mathrm{CI}=0.12-1.16, p=0.016, \mathrm{I}^{2}=43.1 \%\right)$ (Fig. 2). Moreover, elagolix with add-back therapy while not as effective as elagolix alone was still significantly better when compared to placebo $(\mathrm{LOR}=2.74, \mathrm{CI}=$ $\left.2.21-3.27, \mathrm{I}^{2}=48.0 \%, p=0.000\right)$. This same trend of elagolix being the most effective, followed by add-back therapy, was also observed in all secondary bleeding endpoints. Concerning suppression of bleeding, elagolix was more effective than both placebo $(\mathrm{LOR}=4.61, \mathrm{CI}=$ $\left.3.96-5.27, \mathrm{I}^{2}=0.0 \%, p=0.000\right)$ and add-back (LOR $=$ $1.50, \mathrm{CI}=1.17-1.83, \mathrm{I}^{2}=0.0 \%, p=0.000$ ) (Fig. 3a). The same was also true regarding placebo $(\mathrm{LOR}=4.51, \mathrm{CI}=$ $\left.3.82-5.20, \mathrm{I}^{2}=0.0 \%, p=0.000\right)$ and add-back (LOR $=$ $\left.1.45, \mathrm{CI}=1.12-1.78, \mathrm{I}^{2}=0.0 \%, p=0.000\right)$ therapy in amenorrhea (Fig. 3b).

Patients in the phase 2 trials who were given elagolix were observed to have had significant improvement $(>1$ $\mathrm{mg} / \mathrm{dL}$ increase) in their hemoglobin levels compared to the placebo group (elagolix alone vs PBO: $\mathrm{LOR}=1.44$, $\mathrm{CI}=0.6-2.22, \mathrm{I}^{2}=66.0 \%, p=0.000$; elagolix $\mathrm{w} /$ addback therapy vs PBO: $\mathrm{LOR}=1.22, \mathrm{CI}=0.78-1.66, \mathrm{I}^{2}=$ 


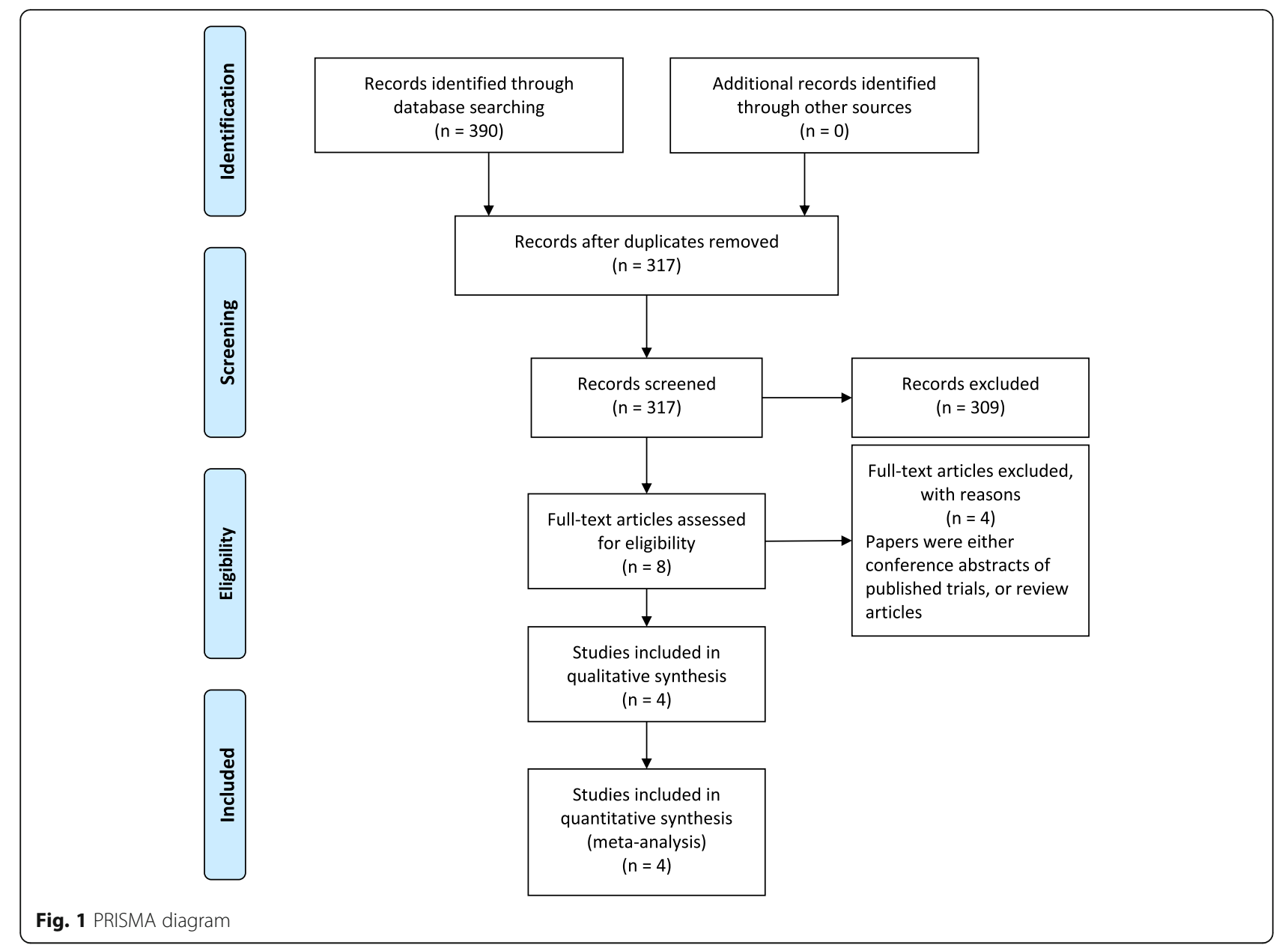

$0.0 \%, p=0.000$ ) (Fig. 4). Interestingly, this outcome did not differ significantly between patients given add back therapy and those given elagolix alone (elagolix alone vs elagolix w/add-back therapy: $\mathrm{LOR}=0.21, \mathrm{CI}=-0.59$ to $1.01, \mathrm{I}^{2}=68.2, \mathrm{p}=0.607$ ). While the phase 3 trials instead reported the number of women with both baseline hemoglobin $\leq 10.5 \mathrm{~g} / \mathrm{dL}$ and who observed an increase of $\geq 2 \mathrm{~g} / \mathrm{dL}$, these results were similar to those from the aforementioned studies. There was significant variation with this respect to this outcome between the three treatment groups (UF1: $p<0.001$; UF2: $p<0.02$ ). However, it can be inferred that this outcome did not vary significantly between elagolix alone and elagolix with add-back therapy (UF-1: elagolix alone difference from $\mathrm{PBO}=49.7 \%, \mathrm{CI}=30.27-69.18$, elagolix $\mathrm{w} /$ add-back therapy difference from $\mathrm{PBO}=45.4 \%, \mathrm{CI}=26.9-63.92$; UF-2: elagolix alone difference from $\mathrm{PBO}=19.2 \%, \mathrm{CI}=$ -6.0 to 44.3 , elagolix $w /$ add-back therapy difference from $\mathrm{PBO}=29.2 \%, \mathrm{CI}=7.6-50.7$ ).

With reference to serious adverse events (life-threatening complications that resulted in discontinuation of treatment), neither group varied significantly as compared to the other two (Fig. 5). On the other hand when comparing overall adverse effects, no significant difference was found between patients receiving placebo and add-back therapy $(\mathrm{LOR}=0.19 \mathrm{CI}=-0.10$ to $0.48 \mathrm{I} 2=$ $0.0 \%, p=0.194)$. In contrast patients receiving elagolix experienced a higher incidence of adverse events than both placebo $\left(\mathrm{LOR}=0.84 \mathrm{CI}=0.48-1.20 \mathrm{I}^{2}=7.8 \% p=\right.$ 0.000 ) and add-back (LOR $=0.68, \mathrm{CI}=0.09-1.26, p=$ $0.024, \mathrm{I}^{2}=64.6 \%$ ) (Fig. 6). Further analysis revealed that hot flashes, nausea, and headaches were the only reported adverse effects that varied in incidence based on the treatment (Fig. 7, Supplemental Figures 1-3). Hot flashes were reportedly higher in the elagolix only treatment group compared to both placebo $(\mathrm{LOR}=2.81, \mathrm{CI}$ $\left.=2.34-3.29, p=0.00, \mathrm{I}^{2}=0.0 \%\right)$ and add-back groups $\left(\mathrm{LOR}=1.66, \mathrm{CI}=1.29-2.03, p=0.0, \mathrm{I}^{2}=22.8 \%\right)$. On the other hand, nausea was significantly higher in the add back group compared to the elagolix only group $\left(\mathrm{LOR}=0.77 \mathrm{CI}=0.30-1.24, p=0.001, \mathrm{I}^{2}=0.0 \%\right)$. Furthermore, the incidence of headaches was significantly lower in the placebo group when compared to both the interventions ( $\mathrm{E}$ vs $\mathrm{PBO}$ : $\mathrm{LOR}=0.75, \mathrm{CI}=0.28-1.21, p$ $=0.002, \mathrm{I}^{2}=0.0 \%$; EA vs PBO: $\mathrm{LOR}=0.48, \mathrm{CI}=0.02-$ $0.94, p=0.042, \mathrm{I} 2=0.0 \%$ ). 
Table 1 Basic study characteristics

\begin{tabular}{|c|c|c|c|c|c|}
\hline Study & Study design & $\begin{array}{l}\text { Duration of } \\
\text { treatment/ } \\
\text { follow-up }\end{array}$ & Country & Population & Intervention \\
\hline $\begin{array}{l}\text { Archer et al. } \\
\text { (NCT01441635) }\end{array}$ & $\begin{array}{l}\text { Phase 2a, dose-ranging, } \\
\text { multiple-cohort study }\end{array}$ & $\begin{array}{l}\text { - 3-month } \\
\text { treatment } \\
\text { - 3-month } \\
\text { follow-up }\end{array}$ & $\begin{array}{l}\text { USA (including } \\
\text { Puerto Rico) }\end{array}$ & $\begin{array}{l}\mathrm{PBO}=50 \\
\text { Elagolix } \\
100 \mathrm{BD}= \\
33 \\
\text { Elagolix } \\
200 \mathrm{BD}= \\
35 \\
\text { Elagolix } \\
300 \mathrm{BD}= \\
30 \\
\text { Elagolix } \\
400 \mathrm{QD}= \\
32 \\
\text { Elagolix } \\
600 \mathrm{QD}= \\
30 \\
\mathrm{E} 200+ \\
0.5 \mathrm{E} 2 / \\
0.1 \mathrm{NETA}= \\
34 \\
\text { E300 + CEP } \\
=26\end{array}$ & $\begin{array}{l}\text { Elagolix only = Elagolix } 100 \text { mg BD; Elagolix } 200 \text { mg } \\
\text { BD; Elagolix } 300 \text { mg BD; Elagolix } 400 \text { mg QD; Elagolix } \\
600 \text { mg QD; Elagolix +ABT = Elagolix } 300 \text { mg + CEP } \\
\text { (continuous low-dose } 1.0 \text { mg E2 continuously and } \\
\text { cyclical oral Progesterone } 200 \text { mg); Elagolix } 200 \text { mg } \\
\text { BD + } 0.5 \text { mg E2/0.1 mg NETA }\end{array}$ \\
\hline \multirow[t]{2}{*}{$\begin{array}{l}\text { Carr et al. } \\
\text { (NCT01817530) }\end{array}$} & $\begin{array}{l}\text { Phase } 2 \mathrm{~b} \text {, double-blind, } \\
\text { randomized, placebo- } \\
\text { controlled, parallel-group } \\
\text { study }\end{array}$ & $\begin{array}{l}\text { - 6-month } \\
\text { treatment } \\
\text { - 6-month } \\
\text { follow-up }\end{array}$ & $\begin{array}{l}\text { United States } \\
\text { (including Puerto } \\
\text { Rico), Canada, } \\
\text { Chile, } \\
\text { and the United } \\
\text { Kingdom }\end{array}$ & $\begin{array}{l}\text { PBO = 65 } \\
\text { Elagolix } \\
\text { only }=65 \\
\text { Elagolix }+ \\
0.5 \text { E2/ } \\
0.1 \mathrm{NETA}= \\
64 \\
\text { Elagolix + } \\
1.0 \mathrm{E} 2 / \\
0.5 \mathrm{NETA}= \\
65\end{array}$ & $\begin{array}{l}\text { Placebo } \\
\text { Elagolix only = Elagolix } 300 \mathrm{mg} \text { BD; Elagolix + ABT = } \\
\text { Elagolix } 300 \mathrm{mg}+0.5 \mathrm{mg} \text { E2/0.1 mg NETA; Elagolix } \\
300 \mathrm{mg}+1.0 \mathrm{mg} \mathrm{E2} / 0.5 \mathrm{mg} \text { NETA }\end{array}$ \\
\hline & & & & $\begin{array}{l}\text { PBO = } 78 \\
\text { Elagolix } \\
\text { only }=77 \\
\text { Elagolix }+ \\
0.5 \text { E2/ } \\
0.1 \mathrm{NETA}= \\
76 \\
\text { Elagolix + } \\
1.0 \mathrm{E} 2 / \\
0.5 \mathrm{NETA}= \\
77\end{array}$ & $\begin{array}{l}\text { Placebo } \\
\text { Elagolix only = Elagolix } 600 \mathrm{mg} \text { QD; Elagolix + ABT = } \\
\text { Elagolix } 600 \mathrm{mg}+1.0 \mathrm{mg} \text { E2/0.5 mg NETA; Elagolix + } \\
\text { ABT = Elagolix } 600 \mathrm{mg}+0.5 \mathrm{mg} \mathrm{E2/0.1} \mathrm{mg} \mathrm{NETA}\end{array}$ \\
\hline $\begin{array}{l}\text { Elaris UF-1 } \\
\text { (NCT02654054) }\end{array}$ & $\begin{array}{l}\text { Phase 3, double-blind, ran- } \\
\text { domized, placebo- } \\
\text { controlled }\end{array}$ & $\begin{array}{l}\text { - 6-month } \\
\text { treatment } \\
\text { - 12-month } \\
\text { follow-up }\end{array}$ & $\begin{array}{l}\text { United States } \\
\text { (including Puerto } \\
\text { Rico) }\end{array}$ & $\begin{array}{l}\text { PBO }=102 \\
\text { Elagolix } \\
\text { only }=104 \\
\text { Elagolix }+ \\
\text { ABT }=206\end{array}$ & $\begin{array}{l}\text { Placebo } \\
\text { Elagolix only = Elagolix } 300 \mathrm{mg} \text { BD; Elagolix }+ \text { ABT = } \\
\text { Elagolix } 300 \mathrm{mg}+1.0 \mathrm{mg} \text { E2/0.5 mg NETA }\end{array}$ \\
\hline $\begin{array}{l}\text { Elaris UF-2 } \\
\text { (NCT02691494) }\end{array}$ & $\begin{array}{l}\text { Phase 3, double-blind, ran- } \\
\text { domized, placebo- } \\
\text { controlled }\end{array}$ & $\begin{array}{l}\text { - 6-month } \\
\text { treatment } \\
\text { - 12-month } \\
\text { follow-up }\end{array}$ & $\begin{array}{l}\text { USA (including } \\
\text { Puerto Rico) and } \\
\text { Canada }\end{array}$ & $\begin{array}{l}\text { PBO }=94 \\
\text { Elagolix } \\
\text { only }=95 \\
\text { Elagolix }+ \\
\text { ABT }=189\end{array}$ & $\begin{array}{l}\text { Placebo } \\
\text { Elagolix only = Elagolix } 300 \mathrm{mg} \text { BD; Elagolix }+ \text { ABT = } \\
\text { Elagolix } 300 \mathrm{mg}+1.0 \mathrm{mg} \text { E2/0.5 mg NETA }\end{array}$ \\
\hline
\end{tabular}

Analysis of the risk of bias across studies concerning the primary outcome revealed no significant publication bias as evidenced by the funnel plot and results of the harbord-egger test (Supplemental Figure 4). Additionally, leave one out sensitivity analysis showed that the pooled result for the primary outcome did not vary significantly with the exclusion of any specific study from the analysis (Supplemental Figures 5-7).

\section{Discussion}

As discussed, while elagolix is a well-established treatment option for pain associated with endometriosis [20]; 
Table 2 Outcomes assessed

\begin{tabular}{|c|c|}
\hline Efficacy combined & Safety combined \\
\hline $\begin{array}{l}\text { Primary endpoints: } \\
\text { 1. Percentage of women who had menstrual blood loss volume of less than } \\
80 \mathrm{~mL} \text { at the final month and a } 50 \% \text { or greater reduction in menstrual } \\
\text { blood loss volume from baseline to the final month. } \\
\text { 2. Mean and percentage change in MBL from baseline to last complete } \\
\text { treatment cycle (last } 28 \text { days) } \\
\text { 3. Percentage of bleeding days } \\
\text { 4. Percentage of women with suppression of bleeding and amenorrhea } \\
\text { 5. Posttreatment return to menses } \\
\text { 6. Changes in hemoglobin concentrations } \\
\text { Secondary endpoints: } \\
\text { 1. Change from baseline in the volume of the fibroid and the uterus (both } \\
\text { assessed using ultrasound evaluation) } \\
\text { 2. Change from baseline in Uterine Fibroid Symptom Quality of Life (UFS- } \\
\text { QoL) questionnaire scores } \\
\text { 3. The number of bleeding days* } \\
\text { 4. Patient Global Impression of Change (PGIC) questionnaire for menstrual } \\
\text { bleeding and non-bleeding uterine fibroid symptoms* } \\
\text { 5. Change and percent change from baseline in fibroid and uterine volume } \\
\text { 6. Change from baseline for the EuroQoL-5D (EQ-5D-5L)* } \\
\text { 7. The Health Care Resource Utilization (HCRU) questionnaire* } \\
\text { 8. Change from baseline for the WPAl* }\end{array}$ & $\begin{array}{l}\text { 1. Incidence and severity of adverse events (AEs), including AEs of } \\
\text { special interest (e.g., hypoestrogenic AEs; osteoporosis and osteopenia; } \\
\text { anaphylactic reaction; severe cutaneous adverse reactions and drug- } \\
\text { induced rash; depression and suicide or self-injury) } \\
\text { 2. Clinical laboratory assessments, including lipid panel } \\
\text { 3. Clinically meaningful changes in ultrasound evaluation (e.g., ovarian } \\
\text { cysts) } \\
\text { 4. Bone mineral density. } \\
\text { 5. Relationship to the study drug (reasonable possibility or no } \\
\text { reasonable possibility) }\end{array}$ \\
\hline
\end{tabular}

*ULF-1/2 only, ${ }^{a}$ Carr et al. only

its use for the treatment of HMB is a novel idea, with all clinical trials having been conducted in the past 3 years. This meta-analysis summarizes the results of 4 randomized control trials encompassing a total of 916 patients, evaluating the efficacy and safety of elagolix and elagolix with add-back as compared to placebo for the treatment of HMB in patients with uterine fibroids.

The results of our meta-analysis found a significantly positive correlation between the administration of elagolix (both with or without add back therapy) and the achievement of the primary study endpoint (reduction of menstrual blood volume to $<80 \mathrm{ml}$ per month and a greater than $50 \%$ decrease from baseline). The inclusion of add-back therapy in the treatment regimen resulted in a decrease $(\mathrm{LOR}=0.64, \mathrm{CI}$ $=0.12-1.16)$ in the number of patients who achieved the primary outcome, However, elagolix even with add-back therapy was a significant improvement over placebo. These findings are consistent with the results of each individual trial and suggest that elagolix without add-back therapy is the most effective management for heavy menstrual bleeding in patients of uterine leiomyomas. The heterogeneity for each pairwise comparison was acceptable $\left(\mathrm{I}^{2}<50 \%, p>0.1\right)$, thereby lending credence to these findings. Furthermore, the evidence from the trials was evaluated to be of high quality (Table 4), which in conjunction with the lack of publication bias (figure S4) speaks to the strength and validity of this and all subsequent analysis.

Elagolix is a non-peptide oral gonadotropinreleasing hormone $(\mathrm{GnRH})$ antagonist which competitively inhibits the $\mathrm{GnRH}$ receptors in the pituitary gland [21]. Its oral administration was reported by previous research to quickly suppress LH levels in a dose dependent manner; this effect being less prominent for FSH [22]. This in turn decreases the production of the main ovarian hormones: estrogen and progesterone [23]. A conclusion was therefore reached that elagolix allows for modulation of gonadotropin and ovarian hormone concentrations, with a partial suppression at lower doses and nearly full suppression at higher ones $[20,21]$. Thus by suppressing pituitary-ovarian axis, elagolix (a GnRH antagonist)

Table 3 Study demographics and baseline clinical characteristics

\begin{tabular}{llllllll}
\hline Study & NCT no. & $\begin{array}{l}\text { Elagolix } \\
\text { dosage }\end{array}$ & $\begin{array}{l}\text { Age } \\
\text { (mean years) }\end{array}$ & BMI* & $\begin{array}{l}\text { Menstrual blood } \\
\text { loss/ ml }\end{array}$ & $\begin{array}{l}\text { Hemoglobin } \\
\text { levels/ } \mathbf{g d L}^{-1}\end{array}$ & $\begin{array}{l}\text { Uterine volume } \\
\text { /cm }^{\mathbf{3}}\end{array}$ \\
\hline Archer & NCT01441635 & $300 \mathrm{BD}$ & $41.6 / 42.6 / 41.6$ & $28.3 / 29.0 / 29.6$ & $334 / 206 / 266$ & $11.0 / 11.3 / 10.3$ & $490 / 576 / 659$ \\
Carr & NCT01817530 & $300 \mathrm{BD}$ & $44.0 / 43.0 / 44.0$ & $30.0 / 30.0 / 30.0$ & $238 / 265 / 296$ & $11.1 / 10.5 / 10.4$ & $627 / 680 / 816$ \\
& & $600 \mathrm{QD}$ & $43.0 / 42.0 / 43.0$ & $30.7 / 31.0 / 31.0$ & $222 / 208 / 247$ & $10.9 / 10.7 / 11.0$ & $570 / 577 / 582$ \\
Elaris UF-1 & NCT02654054 & $300 \mathrm{BD}$ & $41.6 / 42.6 / 42.6$ & $33.8 / 33.4 / 33.3$ & $255 / 249 / 238$ & $11.0 / 10.6 / 11.1$ & $478 / 500 / 475$ \\
Elaris UF-2 & NCT02691494 & $300 \mathrm{BD}$ & $42.5 / 42.2 / 42.5$ & $33.8 / 34.5 / 33.2$ & $254 / 225 / 229$ & $11.0 / 11.0 / 11.1$ & $550 / 537 / 496$ \\
\hline
\end{tabular}

Data is displayed as placebo/elagolix only/elagolix with add-back 
Table 4 Risk of bias analysis

\begin{tabular}{|c|c|c|c|c|c|c|c|}
\hline \multicolumn{8}{|c|}{ Cochrane Risk of Bias Review for RCTs } \\
\hline Study & $\begin{array}{l}\text { Random sequence } \\
\text { generation }\end{array}$ & $\begin{array}{l}\text { Allocation } \\
\text { concealment }\end{array}$ & $\begin{array}{l}\text { Blinding of } \\
\text { personnel }\end{array}$ & $\begin{array}{l}\text { Blinding of outcome } \\
\text { assessment }\end{array}$ & $\begin{array}{l}\text { Incomplete } \\
\text { outcome data }\end{array}$ & $\begin{array}{l}\text { Selective } \\
\text { reporting }\end{array}$ & $\begin{array}{l}\text { Other bias } \\
\text { (ITT analysis) }\end{array}$ \\
\hline Carr et al. & Low risk & Low risk & Low risk & Low risk & Low risk & Low risk & Low risk \\
\hline Elaris (UF-1/2) & Low risk & Low risk & Low risk & Low risk & Low risk & Low risk & Low risk \\
\hline Archer et al. & Unclear risk of bias & Unclear risk of bias & Unclear risk of bias & Unclear risk of bias & Low risk & Low risk & Low risk \\
\hline
\end{tabular}

can significantly decrease the size of uterine leiomyomas, leading to a subsequent decrease in heavy menstrual bleeding [24].

With respect to our secondary bleeding end points of suppression of bleeding and amenorrhea, elagolix alone was shown significantly more likely to lead to both outcomes when compared to either the placebo or the EA groups. A possible explanation for this is provided once more, by its anti-GnRH action.
Oversuppression of the ovarian hormones brought on by elagolix is likely to disrupt the normal menstrual cycle, leading to the observed amenorrhea and suppression of bleeding.

When considering the patient hemoglobin levels, pooled analysis of the phase 2 trials reported a positive correlation between the use of elagolix and the percentage of women who had observed an increase of $\geq 1 \mathrm{~g} / \mathrm{dl}$ in hemoglobin levels. The heterogeneity in

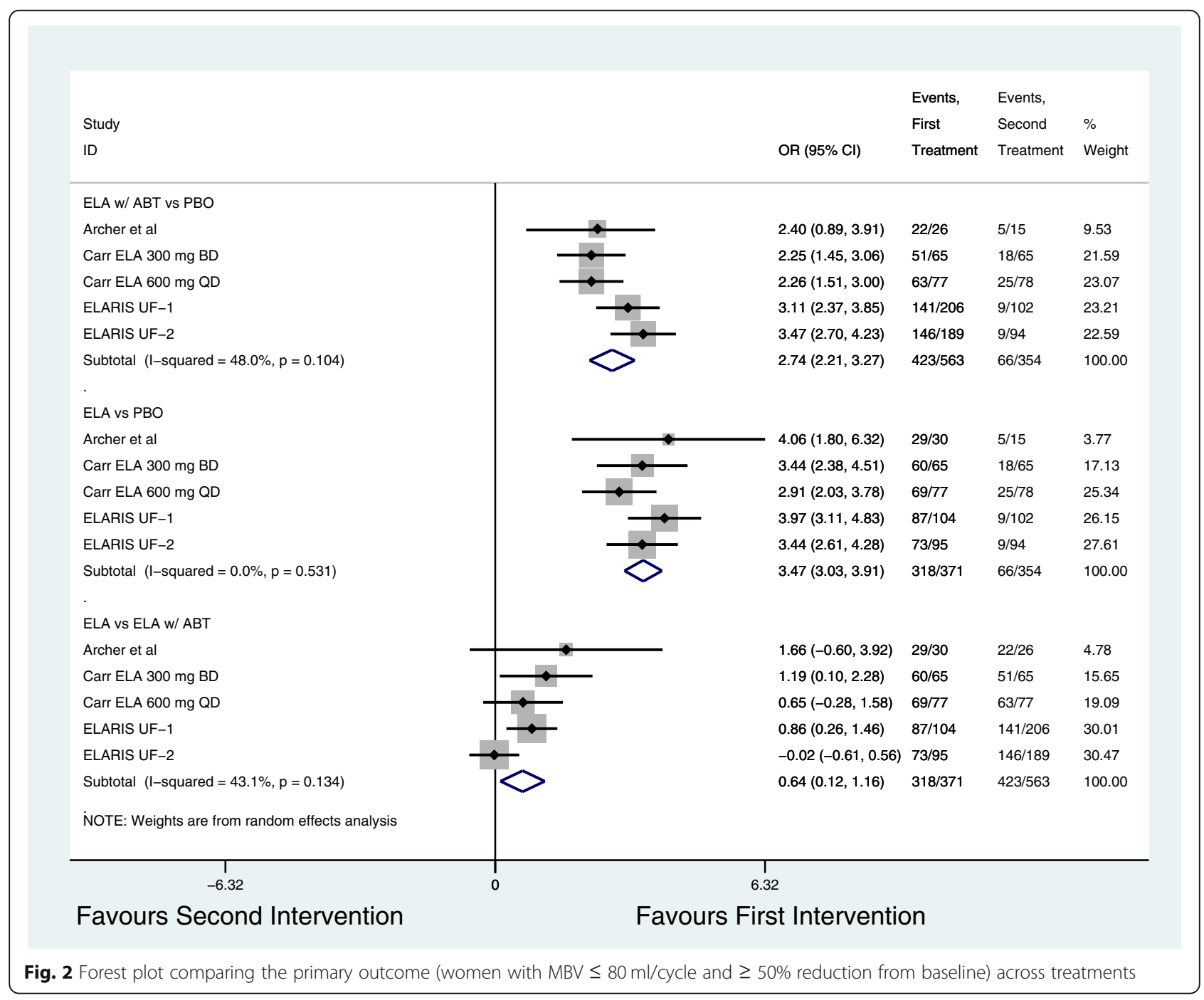



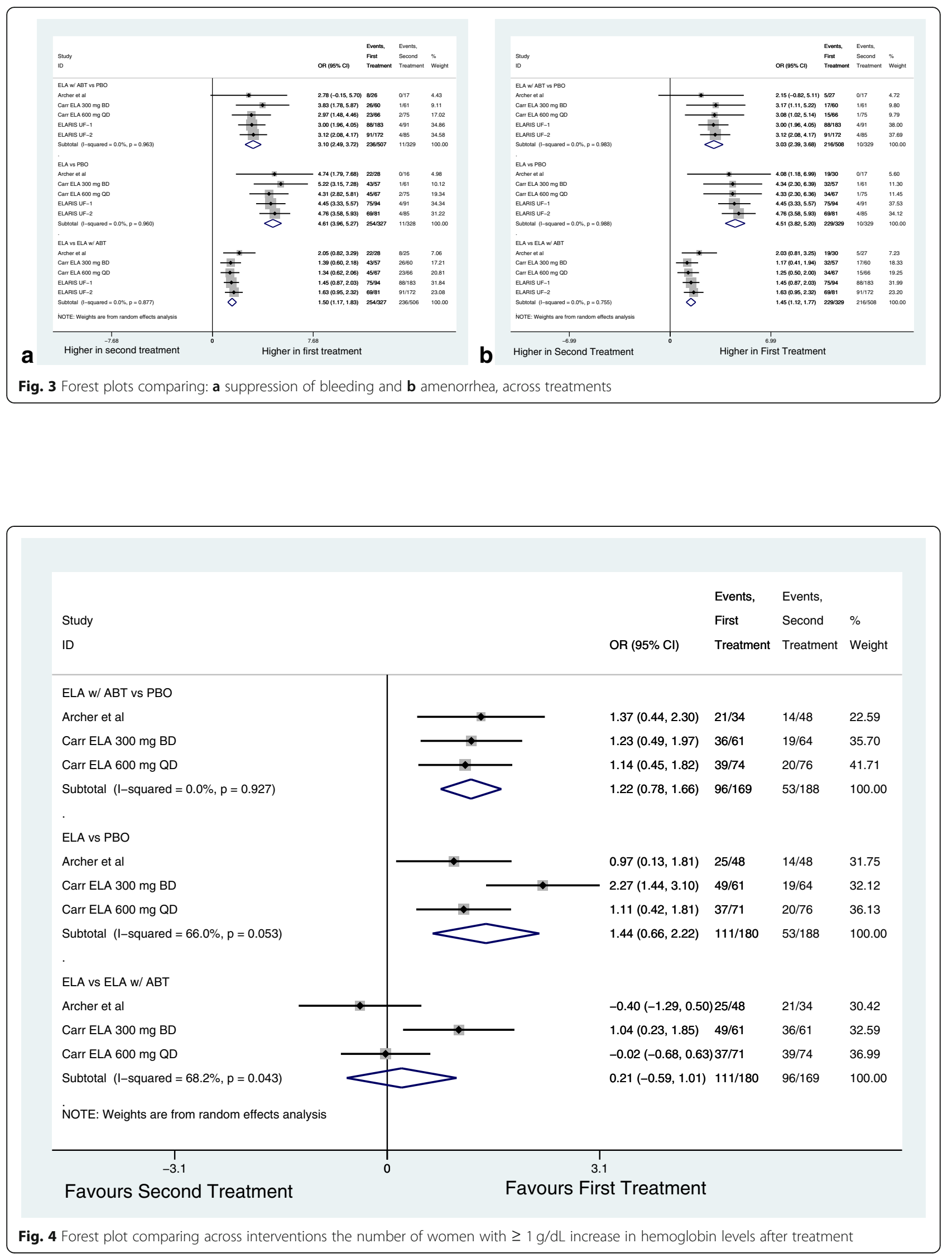


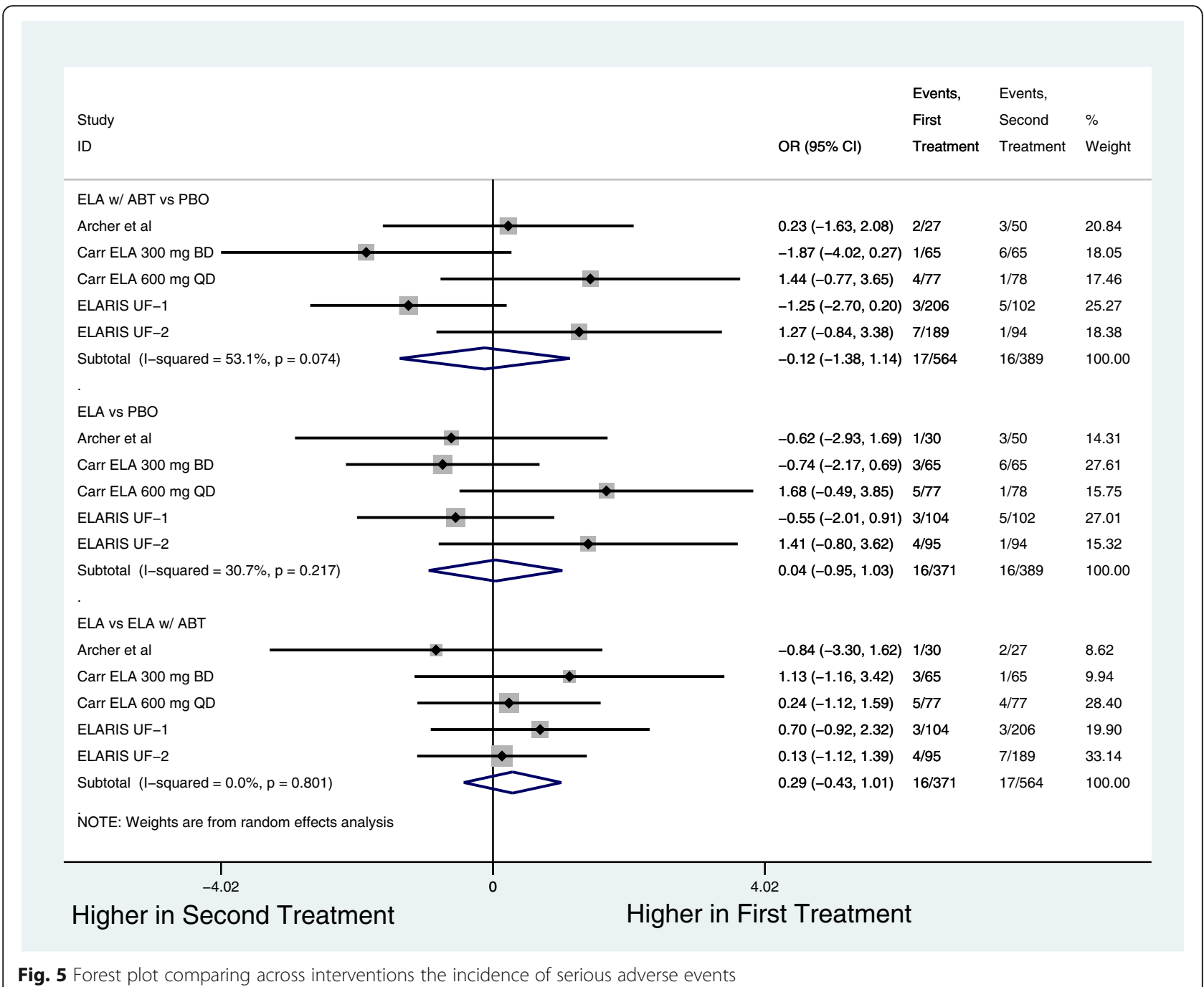

Fig. 5 Forest plot comparing across interventions the incidence of serious adverse events

this analysis while substantial could be explained by the differences in the follow-up periods of the 2 trials. These findings are consistent with the results of the phase 3 trials which similarly reported that elagolix (with or without add-back) significantly improved hemoglobin values. Moreover, the lack of add-back therapy's role in improving hemoglobin levels is further corroborated by the overlapping confidence intervals reported by UF-1 and UF-2 for both interventions (elagolix with and without add-back therapy) compared to placebo, concerning the percentage difference of women who observed $\mathrm{a} \geq 2 \mathrm{~g} / \mathrm{dL}$ increase in hemoglobin levels. While the improvement in hemoglobin levels in the elagolix groups compared to placebo may be attributed to the corresponding decrease in MBL (primary outcome), we found no evidence explaining the lack of difference between the elagolix groups (with and without add-back).
When pooling safety related endpoints, patients given elagolix had a significantly higher overall incidence of adverse events when compared to the placebo group. However, the incidence of serious lifethreatening adverse events was not shown to vary between groups, attesting to the safety of the drug. With the exception of hot flashes, headaches and nausea, most adverse events did not vary significantly between the intervention and placebo group and therefore could not be directly attributed to the drug itself. Furthermore, analysis revealed that headaches and hot flashes were more frequently observed in the elagolix only group, which may be attributed to the estrogen diminishing impact of elagolix $[25,26]$. The high incidence of nausea observed in the add-back group may be due to the side effects of the estradiol administered as part of the add-back treatment regimen. 


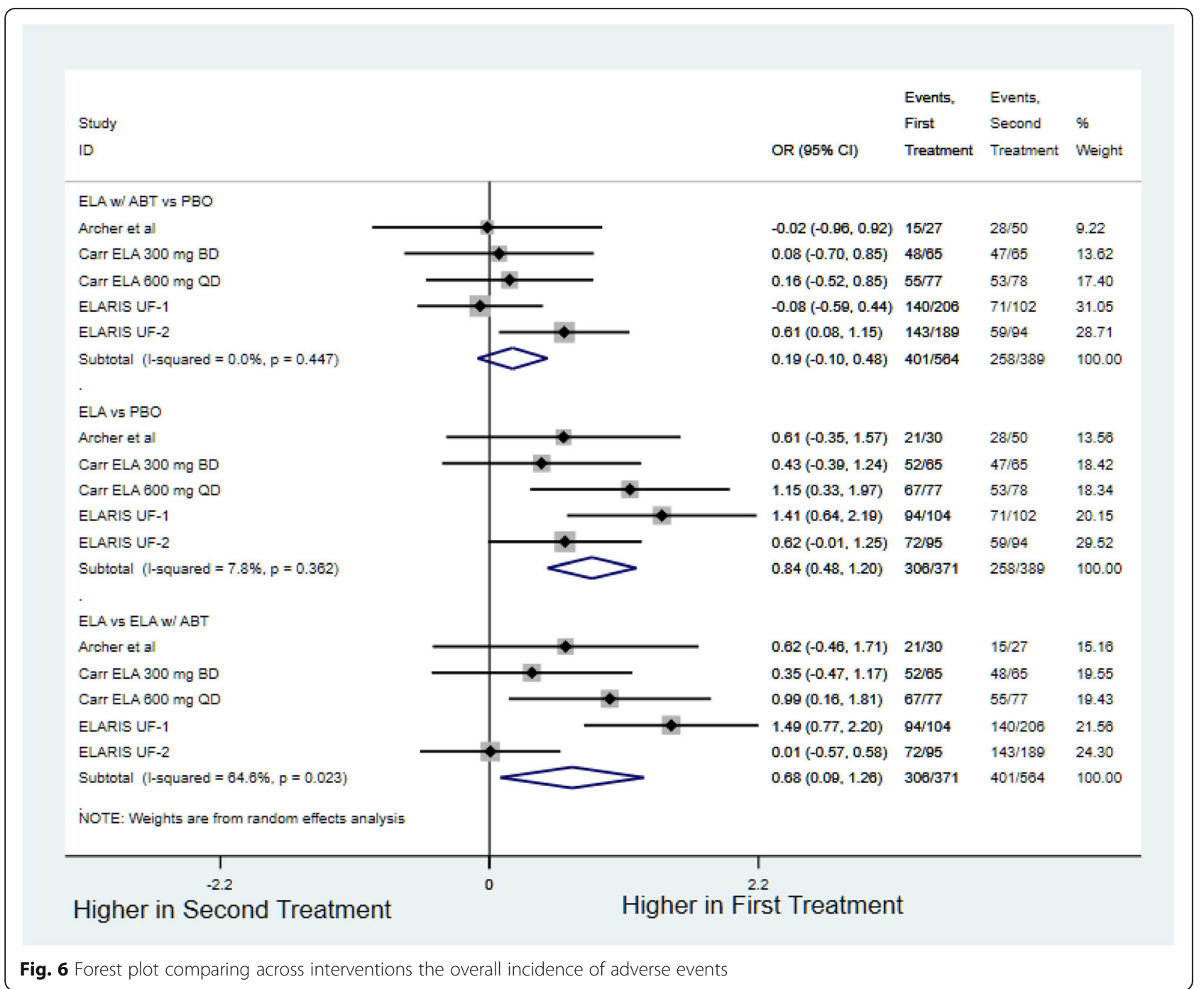

Carr et al. and Schlaff et al. also reported decrease in bone mineral density (BMD) as a secondary side effect of the use of elagolix. All 3 trials reported a significantly decreased BMD in the elagolix only group compared to the placebo group. This is inline with previous studies correlating low serum estrogen levels to loss of BMD [27]. Add-back therapy was shown to be effective in curtailing this loss in bone density, with Schalff et al. reporting no significant difference in BMD between placebo and add-back groups, and Carr reporting the same with one exception (total hip density in the $300 \mathrm{mg}$ BD elagolix arm).

A few limitations should be kept in mind when analyzing the results of this meta-analysis. Firstly because of the novelty of the drug, this analysis only included 4 trials, and more would be required to form a conclusive result. Secondly, any dose- dependent effect of add-back therapy must be investigated to find the perfect balance between the safety and therapeutic of this treatment. Further trials investigating the safety and efficacy of different addback therapies at different doses with elagolix should be conducted in order to reveal a potentially better treatment solution.

\section{Conclusion}

In conclusion, pooling of results from 4 high-quality trials provides strong evidence for the use of elagolix as a treatment option for heavy menstrual bleeding in patients with uterine leiomyomas. Analysis showed marked improvement in all efficacy endpoints taken into consideration in this review. Additionally, trials have demonstrated that the drug is relatively safe, with generally mild to moderate adverse effects and no serious (life-threatening) side- 


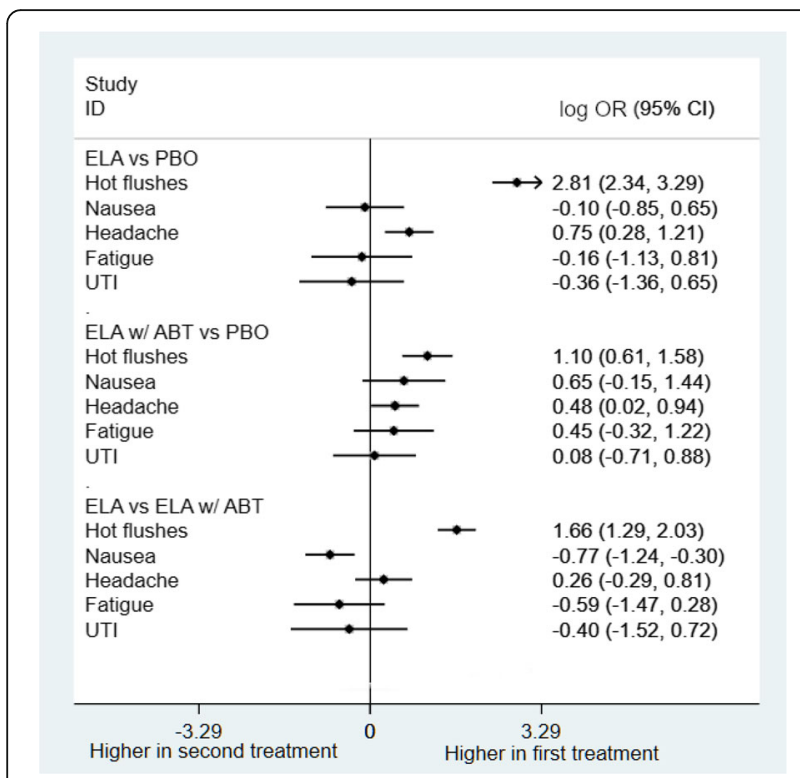

Fig. 7 Pooled effect estimates (log OR) for selected adverse events according to treatment group

effects. Moreover, these results advocate for the use of add-back therapy (combined estradiol and progesterone) with elagolix, as its inclusion in the treatment regimen resulted in a significant attenuation of elagolix-associated hypoestrogenic effects, leading to a much safer therapeutic course.

\section{Abbreviations}

HMB: Heavy menstrual bleeding; MBL: Menstrual blood loss; PBO: Placebo; LOR: Log-odds ratio; Cl: Confidence interval; SPRMs: Selective progesterone receptor modulators; GnRH: Gonadotropin-releasing hormone; RCT: Randomized control trial; CRoB Tool: Cochrane Risk of Bias Tool; BMD: Bone mineral density; E: Elagolix; EA: Elagolix with add-back

\section{Supplementary Information}

The online version contains supplementary material available at https://doi. org/10.1186/s43043-021-00064-5.

Additional file 1: Figure S1. Common adverse events in Elagolix only group (ELA) vs placebo group (PBO). Figure S2. Common adverse events in Elagolix with add-back group (ELA w/ ABT) vs placebo group (PBO). Figure S3. Common adverse events in Elagolix only (ELA) vs Elagolix with Add-back therapy (ELA w/ ABT). Figure S4. Funnel plots for the pooling of the primary outcome: (a) Elagolix vs Placebo; (b) Elagolix with add back vs Placebo; (c) Elagolix vs Elagolix with add back. Figure S5. Leave one out sensitivity analysis for the primary outcome (Elagolix only vs Placebo). Figure S6. Leave one out sensitivity analysis (Elagolix with add-back vs Placebo). Figure S7. Leave one out sensitivity analysis (Elagolix only vs Elagolix with add-back).

\section{Acknowledgements}

Not Applicable

\section{Authors' contributions}

In addition to having read and approved the final manuscript, the following are the contributions of each specific author: MA: conceptualization and design of the study, search and screening of studies, data analysis and interpretation, drafting of the manuscript. AKH: design of the study, final review and editing of the manuscript. $\mathrm{HJ}$ : conceptualization and design of the study, data analysis and interpretation, drafting of the manuscript. FZ: search and screening of studies, data extraction, drafting of the manuscript. ZS: data extraction, review and drafting of the manuscript. The author(s) read and approved the final manuscript.

\section{Funding}

Not applicable.

\section{Availability of data and materials}

Not applicable.

\section{Declarations}

Ethics approval and consent to participate

Not applicable.

\section{Consent for publication \\ Not applicable.}

\section{Competing interests}

Not applicable.

\section{Author details}

'Dow Medical College, Dow University of Health Sciences, Karachi, Pakistan. ${ }^{2}$ Obstetrics \& Gynaecology Unit I, Dow University of Health Sciences, Karachi, Pakistan.

Received: 23 March 2021 Accepted: 11 June 2021

Published online: 05 July 2021

\section{References}

1. Farris M, Bastianelli C, Rosato E, Brosens I, Benagiano G (2019) Uterine fibroids: an update on current and emerging medical treatment options. Ther Clin Risk Manag. 15:157-178

2. ARW W (2017) Uterine fibroids - what's new? F1000Res 7:6 Available from: https://www.ncbi.nlm.nih.gov/pmc/articles/PMC5721931/. [cited 2020 Apr 17]

3. Zimmermann A, Bernuit D, Gerlinger C, Schaefers M, Geppert K (2012) Prevalence, symptoms and management of uterine fibroids: an international internet-based survey of 21,746 women. BMC Womens Health 12:6

4. Maheux R (1989) Treatment of uterine leiomyomata: past, present and future. Horm Res. 32(Suppl 1):125-133

5. Gordon AG, Magos AL (1989) The development of laparoscopic surgery. Baillieres Clin Obstet Gynaecol. 3(3):429-449

6. Sohn GS, Cho S, Kim YM, Cho C-H, Kim M-R, Lee SR (2018) Current medical treatment of uterine fibroids. Obstet Gynecol Sci. 61 (2):192-201

7. Batzer FR (2006) GnRH analogs: options for endometriosis-associated pain treatment. J Minim Invasive Gynecol. 13(6):539-545

8. Ezzati M, Carr BR (2015) Elagolix, a novel, orally bioavailable GnRH antagonist under investigation for the treatment of endometriosis-related pain. Womens Health Lond Engl. 11(1):19-28

9. Surrey E, Taylor HS, Giudice L, Lessey BA, Abrao MS, Archer DF et al (2018) Long-term outcomes of elagolix in women with endometriosis: results from two extension studies. Obstet Gynecol. 132(1):147-160

10. NCT03886220. A study to evaluate the safety and efficacy of elagolix for the management of heavy menstrual bleeding associated with uterine fibroids in premenopausal women. https://clinicaltrials.gov/show/NCT03886220. 2019; Available from: https://www.cochranelibrary.com/central/doi/10.1002/ central/CN-01911892/full

11. Long-term safety study of elagolix in combination with estradiol/ norethindrone acetate for the management of heavy menstrual bleeding associated with uterine fibroids in premenopausal women - full text view ClinicalTrials.gov. Available from: https://clinicaltrials.gov/ct2/show/NCT032 71489. [cited 2020 Apr 17]

12. Borah BJ, Nicholson WK, Bradley L, Stewart EA (2013) The impact of uterine leiomyomas: a national survey of affected women. Am J Obstet Gynecol 209(4):319.e1-319.e20

13. Ding C, Wang J, Cao Y, Pan Y, Lu X, Wang W et al (2019) Heavy menstrual bleeding among women aged 18-50 years living in Beijing, 
China: prevalence, risk factors, and impact on daily life. BMC Womens Health. 19(1):27

14. Wang W, Bourgeois T, Klima J, Berlan ED, Fischer AN, O'Brien SH (2013) Iron deficiency and fatigue in adolescent females with heavy menstrual bleeding. Haemophilia. 19(2):225-230

15. Moher D, Liberati A, Tetzlaff J, Altman DG. Preferred reporting items for systematic reviews and meta-analyses: the PRISMA statement. BMJ. 2009; 339. Available from: https://www.bmj.com/content/339/bmj.b2535. [cited 2020 Apr 17]

16. Higgins JPT, Altman DG, Gøtzsche PC, Jüni P, Moher D, Oxman AD, et al. The Cochrane Collaboration's tool for assessing risk of bias in randomised trials. The BMJ. 2011;343. Available from: https://www.ncbi.nlm.nih.gov/ pmc/articles/PMC3196245/. [cited 2020 Apr 15]

17. Archer D, Stewart E, Jain R, Feldman R, Lukes A, North J et al (2017) Elagolix for the management of heavy menstrual bleeding associated with uterine fibroids: results from a phase 2a proof-of-concept study. Fertil Steril 108(1): 152-160.e4

18. Carr BR, Stewart EA, Archer DF, Al-Hendy A, Bradley L, Watts NB et al (2018) Elagolix alone or with add-back therapy in women with heavy menstrual bleeding and uterine leiomyomas: a randomized controlled trial. Obstet Gynecol. 132(5):1252-1264

19. Schlaff WD, Ackerman RT, Al-Hendy A, Archer DF, Barnhart KT, Bradley LD et al (2020) Elagolix for heavy menstrual bleeding in women with uterine fibroids. N Engl J Med. 382(4):328-340

20. ORILISSA (Elagolix) for tpain associated with endometriosis. Clinical Trials Arena. Available from: https://www.clinicaltrialsarena.com/projects/orilissaElagolix-treatment-pain-associated-endometriosis/. [cited 2020 Apr 15]

21. Hornstein MD (2017) An oral GnRH antagonist for endometriosis - a new drug for an old disease. N Engl J Med. 377(1):81-83

22. Struthers RS, Chen T, Campbell B, Jimenez R, Pan H, Yen SSC et al (2006) Suppression of serum luteinizing hormone in postmenopausal women by an orally administered nonpeptide antagonist of the gonadotropinreleasing hormone receptor (NBI-42902). J Clin Endocrinol Metab. 91(10): 3903-3907

23. Struthers R, Nicholls A, Grundy J, Chen T, Jimenez R, Yen S et al (2009) Suppression of gonadotropins and estradiol in premenopausal women by oral administration of the nonpeptide gonadotropin-releasing hormone antagonist Elagolix. J Clin Endocrinol Metab. 94(2):545-551

24. Borahay MA, Asoglu MR, Mas A, Adam S, Kilic GS, Al-Hendy A (2017) Estrogen receptors and signaling in fibroids: role in pathobiology and therapeutic implications. Reprod Sci. 24(9):1235-1244

25. Freedman RR (2014) Menopausal hot flashes: mechanisms, endocrinology, treatment. J Steroid Biochem Mol Biol. 142:115-120

26. MacGregor EA, Frith A, Ellis J, Aspinall L, Hackshaw A (2006) Incidence of migraine relative to menstrual cycle phases of rising and falling estrogen. Neurology. 67(12):2154-2158

27. Ettinger B, Pressman A, Sklarin P, Bauer DC, Cauley JA, Cummings SR (1998) Associations between low levels of serum estradiol, bone density, and fractures among elderly women: the study of osteoporotic fractures. J Clin Endocrinol Metab. 83(7):2239-2243

\section{Publisher's Note}

Springer Nature remains neutral with regard to jurisdictional claims in published maps and institutional affiliations.

\section{Submit your manuscript to a SpringerOpen ${ }^{\circ}$ journal and benefit from:}

- Convenient online submission

- Rigorous peer review

- Open access: articles freely available online

- High visibility within the field

- Retaining the copyright to your article

Submit your next manuscript at $\boldsymbol{\nabla}$ springeropen.com 